\title{
Morphology of Pictorial News: The Chameleonic Attributes
}

\author{
Ndoma J. Brown ${ }^{1}$, Chris Chimdubem Ngwu ${ }^{2}$ \\ ${ }^{1}$ Department of Mass Communication, Cross River University of Technology (CRUTECH), Calabar, Cross River State, \\ Nigeria \\ ${ }^{2}$ Department of Mass Communication, Enugu State University of Science and Technology (ESUT), Enugu, Enugu State, \\ Nigeria \\ Correspondence: Ndoma J. Brown, Department of Mass Communication, Cross River University of Technology \\ (CRUTECH), Calabar, Cross River State, Nigeria
}

Received: November 10, 2014 Accepted: November 19, 2014 Online Published: May 15, 2015

doi:10.11114/smc.v3i1.822

URL: http://dx.doi.org/10.11114/smc.v3i1.822

\begin{abstract}
This study looked at the relationship between print media contents and the public's attitude of appreciating news. Accountable facts and records used in this paper were strictly directed to qualifying press pictures as news. In conducting this study, the descriptive research design was used. The result of the hypothesis was tested with 200 readers by using Chi-square statistical calculation. The pictures selected were purposively investigated to establish the influence they possessed. After a thorough analysis, it was concluded that the issue of effective presence of news pictures eould have surfaced because of sharing qualitative level of selective perception that had existed between the news consumers and media publications. It was recommended that irrespective of the medium used to express news worthiness, the chameleonic nomenclature of news pictures should retain neutrality and maintain investigative inkling for this curious news age. $49.7 \%$ respondents read news that had pictures in them than those without pictures. A situation, where press picture connected written news, relished aesthetical glamour and cognitive nostalgia, was uncovered. The summarized efforts, disregarded freehandedness and prioritized ethical ideology in the overcrowded print media racketeering. Hence, institutionalized professionalism was strongly advocated. And expediently, dissonance theory interrelated with three selectivity processes was opined to encourage investigative photojournalism as to promote creativity in the journalistic $2 \mathrm{~W}$ 's and $\mathrm{H}$.
\end{abstract}

Key words: conflict, human interest, impact, oddity, prominence, proximity, timeliness and symbolic argument

\section{Introduction}

In identifying picture as news with regard to print media reportage, its news worthiness for the 21 st century will be essentially unavoidable. This effort was geared towards revitalizing photojournalism as a histrionic entity within the orbit of journalism. A believable fact was that news pictures as investigative, interrogative, inquisitive and interpretative story tellers remain the live-wire in any news story. This invidious approach was not to undermine the vocabulary of news writers, but to suture amiable relationship between the print media content and the public. This will permit privileged opportunities to witness and re-evaluate the factuality in reported news.

This study adopted dissonance theory believing that to understand, predict or control human behaviour in the process of reporting important events, the editor must understand and appreciate the nature of what, why and how are encapsulated in good news reports. To achieve success in journalism practice through print media reportage, the photojournalists and other journalists must ensure and adequately pursue the truth by maintaining consistency with their readerships' interests and beliefs.

\section{Objective of the Study}

For obvious reasons, this study reinforces the operational objectives of photojournalism vis-à-vis checkmating mediocrity. It summarized fully fledged functionality that qualifies photojournalist as the "eye witness" within the bounds of public and media rights. By approximation, this effort places the photojournalists as eagles or hawks equipped with news values that wades in at the swiftest chance for magnificent shots, as every adventurous second is of consequential benefit to visual proficiency.

\subsection{Statement of Hypotheses}

The following hypotheses are stated as a guide to the study: 
$\mathrm{H}_{1}=$ there is a significant relationship between print media contents and the public's appreciation of news.

$\mathrm{H}_{0}=$ there is no significant relationship between print media contents and the public's appreciation of news.

\subsection{Theoretical Framework}

We aptly selected for this study on picture as news, the dissonance theory of attitude change, because it strongly connected with Carl Hovland's selectivity processes. National Open University of Nigeria report (NOUN, 2014, http://nou.edu.ng/) argued that dissonance theory was often confronted by new or conflicting information; people experience a kind of mental discomfort as dissonance. Within such precept, "the print media readers consciously and subconsciously worked to limit or reduce that discomfort through three interrelated selective processes," (Media, 2014, http://mediacarmeliteracy.tumbir.com/). These processes, namely: selective exposure (or selective attention), selective retention and selective perception were employed to determine how the respondents appreciate information given to them. The process of selective exposure held that the print media readers tended to read media messages and symbols that were consistent with their attitudes, interests and beliefs. The process of selective perception on the other hand held that the reading audience interpreted messages and symbols in a "manner consistent with their pre-existing attitudes and beliefs, while the process of selective retention held that people remembered best and longest those messages and symbols that were consistent with their existing attitudes and beliefs" (Baran, 2002, pp. 380 - 381). The processes considered practical observable and verifiable behaviours in understudying comparative analysis of news pictures and news stories. Furthermore, it allowed the readers of the print media reports the opportunity to interpret events based on their understanding of the dynamics of news pictures.

The overall implication of these processes in the practice of photojournalism and the print media reportorial was that firstly, only pictures of interest to the reader were described as being meaningfully expressive. This was, however, biased because what interested the readers about the pictures could be the conceptuality of the news, especially in its morphology, titles or displayed types. Simultaneously, the same picture may not interest another reader. Secondly, it meant that what the readers already had in mind may predetermine which news story to read and which picture to appreciate and not essentially the views of the news editor or sub-editor.

\section{Research Methodology}

We adopted the descriptive research method for this paper. Descriptive research method was an enquiry that dealt with the collection and analyses of data for the sole purpose of describing in detail and interpreting existing conditions and ongoing processes, current practices and attitudes (Ngwu \& Ugwu, 2013). In fact, the main thrust of descriptive research was not just to describe existing state of affairs, but, more importantly, to discover relevance and meaningful implication of visual symbolism. In this paper, we had painstakingly restricted our efforts to provide and make informed descriptions in conformity to the confined objectives of this study. The researchers also sampled the opinion of frequent newspaper readers with the intention of finding out the effect of print media contents on public's appreciation of news with emphasis on the role played by pictures and other visual images.

\subsection{Sample and Sampling Technique}

In this study, the researchers used purposive sampling method to select the pictures and issues from the selected magazines/newspapers for discussion. The researchers selected 50 issues of daily newspaper publication of Punch newspaper that had pictorial news dated from $1^{\text {st }}$ October, 2014 to $19^{\text {th }}$ November, 2014 along with two issues of monthly newspaper publication of Tell magazine that had pictorial news for the month of October, 2014 and November, 2014. The researchers then did a descriptive analysis of these selected pictures and issues with a general survey of the opinion of 200 readers of the same issues reviewed while the data from the respondents were analyzed using Chi-square statistical tool. The major characteristic for selecting stories in each of the magazine and newspaper was the existence of pictures in them. The literature reviewed in this study so far has been elaborate and has traced enormous relevance to the topic.

\section{Pictures as Visual Symbols for Argument}

Obviously, visual arguments come in many different forms and use many different media. Artists, photographers, advertisers and designers approach their works with the same intentions that authors of written materials do - they want to share a point of view, present an idea, inspire or evoke a reaction, (Goshgarian, Krueger, \& Minc, 2003, p. 174). And invariably, pictures as "nonverbal communication - within an entire communication process - which must be viewed as a whole, is greater than the sum of its parts. Naturally, humans learn mostly when a nonverbal message reinforces a verbal message, meaning is conveyed quickly and easily, and with increased comprehension," (Highered, 2014, http:/highered.mcgraw-hill.com/). In some print media reportorial, symbols are introduced to intensify anxiety and establish concealment of motive, in-order to avoid character assassination, (see Figure 1). This was identified in the action of using a long wig as symbol for argument that represented the judiciary (circled) in-which such communication 
creates curiosity and suspicion.

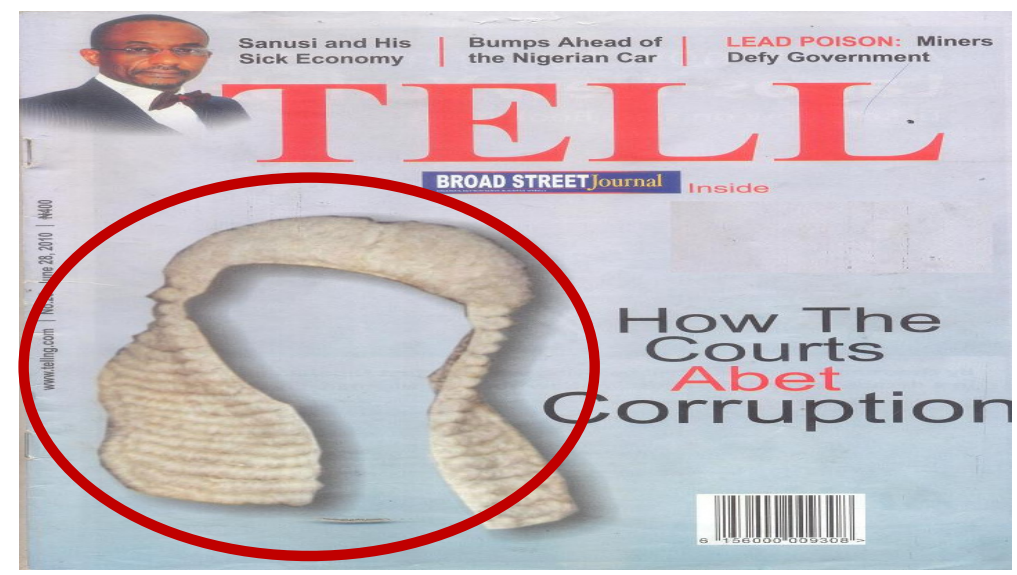

Figure1. A symbol of a long wig (circled) represented an unknown judge

Source: Tell magazine, cover page, June $28^{\text {th }}, 2010$.

According to Weiser (2009), nonverbal communication in photojournalism is a form of journalism that records and presents factual stories or features for publication by combination of pictures and text with primary emphasis on the pictorial approach and presentation (Weiser, 2009, http://www.phototherapy-centre.com/). By implication, this is what photojournalism is all about ... just a form of journalism which employs images in order to tell a news story. It is now usually understood to refer only to still images... and how they work within the same ethical approach to objectivity which is often applied by other journalists. In fact, what to shoot, how to frame and how to edit are usually constant considerations (Photo-chart, 2014, http://www.Photochart.com/). Therefore, according to Wogu (2005), "whatever form one decides to conceptualize it, photojournalism is simply the transmission of messages through pictures," (p. 280).

Most significantly, print media communications are bound by large, bold headlines with big, dramatic pictures and short, easy-to-read stories. These are tactics used by newspaper graphic designers to attract news readers and such displays are not strange (Lester, 2011, p. 88). Irrespective of these glaring impacts of visual communication in the print media reportorial, as critical readers of written arguments, the author is not taken at face value. One considers the author's purpose and intent, readership, style, tone, and supporting evidence. One must apply these same analytical tools to effectively read visual language requiring a close examination and interpretation of the premise, claims, details, supporting evidence, and stylistic touches embedded in any visual piece. Like the work of art, pictures often employ colour, shape, line, texture, depth, and point of view to create their effect. Therefore, to understand how pictures work and to analyze the way pictures persuade, one must also ask questions about specific aspects of form and design. For example, some questions to ask about print images such as those in newspaper and magazine are: What in the frame catches one's attention immediately? What is the central image? What is the background image? What are the foregrounded images? What are the surrounding images? What is significant in the placement of these images? What is their relationship to one another? What verbal information is included? How is it made prominent? How does it relate to the other graphics or images? What specific details (people, objects, and locale) are emphasized? Which of these are exaggerated or idealized? What is the effect of colour and lighting? What emotional effect is created by the images pleasure? Longing? Anxiety? Nostalgia? Do the graphics and images make one want to know more about the subject or product? Is there any symbolic meaning imbedded in the images (Goshgarian, Krueger, \& Minc, 2003, p. 175). And if the different elements within the pictorial framework are not related, there is bound to be confusion and misdirection. Erroneously, there are also symbolic conflicts, when pictures resist the opportunity of other elements the visual rights to survive. See photo blocking letters "ch" in Figure 5. This visual entropy established literary inconsistency in the publishers' nameplate, which by extension entrained confusion in readership.

There is also a simpler form of concluding that an event in picture form is one thing as it has happened and another thing as it comprehended, and of the comprehension there are many forms. This is a necessary statement if one wants to approach an understanding of photography as modern art (Hess, 1975, p. 7). At the appreciation stage of picture, a good photojournalist should be like a good reporter; he/she should always look for the unusual angle in his/her assignment. His/her picture must be able to tell the story like it is, because pictures never lie, (Akinfeleye, 2011, p. 87). Akinfeleye (2011) went on to consider "pictures in three variables: the representational aspect, form and the expressive nature of picture. In this study, emphasis was laid on the expressiveness of picture. Here, the expressive nature of the press pictures was synonymous with expressive journalism. In maintaining a sound visual action, the photojournalists also 
protected and secured their supportive cut-lines. This was to present brief and punchy news in pictures and texts," (p. $85)$.

\section{Expressions of News Values in Pictures}

Realistically, in the photojournalistic world, the definition of what constitutes news has been evolving over the years as the profession itself, like the function of the media, which in simple terms are 'to inform, to educate and entertain'. But as society continues to develop with attending complexities in socio-economic and political engineering, so has the functions of the media expanded. The roles now include, setting positive national values, promoting national and international cohesion and stability, through the social responsibility role of the media. It is, therefore, the total consideration of the foregoing that could, at any point, determine what news is to the investigative and interpretative photojournalist in any particular environment. Before now, some analysts had variously tried to define news pictures as an unusual event, event of public interest, a sudden development. However, developments in the media and the world have placed the photojournalists and their editors as the ultimate determinants of what constitutes news or a newsworthy event (Effiom, 2005, pp. 6-7).

A picture is news. When something happens, it is recorded by photojournalists, who package it in a form that could be understood by a reader and publishes it through a medium. Many events worth reporting take place at the same time in different places. The one that gets selected, gets highlighted, and gets published as news. Except an account of an event passes through this process, it is no news. News-photo is a report that presents a contemporary view of reality with regard to a specific issue, event or process (Defleur and Everett, 2013, http://www.amazon.com/).

Affirmatively, in the case of reporting news in pictures, news-photo occurs as the report of an event which both the editor and the photojournalist consider effective medium for publication (Nwabueze, 2011, p. 2). Subjectively, investigative photography is the most basic reason in photographic communication which tends to overlap into other reasons. Investigative reporting is not just doing interviews and collecting written documents to add up to the independent observations of the reporter. Pictures that tell the story are also used to back up the investigation (Nwabueze, 2012, p. 147). From that perspective, some news pictures that appear on particular pages represent the theme of their editorial content. Pictures as 'Photosynthesis' in Newswatch magazine and cover page illustrations in Tell magazines are often introduced to represent their editorial voices.

Akpan (2000) writes that:

In most cases, an editorial picture is an argument. As a communication form, it is very rhetorical in nature, in that it has to use every available means of persuasion. There are, therefore, two very important segments of an editorial picture: (a) a brief display of a current event, this has to be an event of significance and (b) interpretation, an appraisal of that event, for the sole purpose of getting the reader or viewer to think like the photojournalist. The event must have been reported somewhere in the media, and the editorial photojournalist is trying to throw more light on the issue. For one to be able to appreciate good editorial pictures one needs to be familiar with rhetoric. Rhetoric, as the art of using every available means of persuasion, compels the editorial photojournalist to approach editorial photography from the angle of group dynamics by shunning frivolous tendencies and encouraging 'win win' and 'generality' tendencies (p. 68).

A generally held notion of news picture is that it is what photojournalists or the news media say that becomes news. Unavoidably, in the Nigerian version, the news-editors determine what is reported as news, instead of allowing the photojournalists select their news-photos. This study established a disconnection between the photojournalists and news-editors in determining news-worthy pictures. In that vein, how then will the photojournalists remain accountable for pictorial flaws, when they were not allowed to determine what were news pictures in print reportorial? Not minding these unfriendly conditions in Nigeria, the news pictures should be treated with tenacities in news values, qualities, characteristics, or determinants. Photojournalism is simply photo-reporting. And in photo-reporting an event or object, the photojournalist must adhere to the "three-serving servants of photojournalism". These are the 'what,' the 'why' and the 'how.' One will notice that while the photojournalists must approach their news angle of the event by observing the "three serving servants," the reporter approaches his/her own news angle by observing the rule of the "five serving servants" - (that is, the 'who', the 'what', the 'where', the 'when', the 'why' and the 'how'(Akinfeleye, 2011, p. 86). In that regard, a joint effort of photojournalist and news editor should be abreast with what qualifies pictures as investigative and interpretative - based on what, why and how as characterized in the following contingencies:

\subsection{Timeliness}

How current an event or occurrence is, gives news picture, an edge over other events. Breaking news picture gets attention in news reporting. Photojournalists give priority to what is happening now, what is current, that is, more current than competing stories, not what is no longer fresh: If an event happened many days ago, photojournalists look 
for fresh angles to make it current and newsworthy (Nwabueze, 2011, p. 6). This attitude attracted the process of selective exposure, which opined that the readers did not only depend on their consistent interest and beliefs; but also the currency in news will break monotony since picture illustrations are dynamic, see Figure 1.

\subsection{Prominence}

This considers the personality or personalities involved in the investigative news picture. How the involved personalities' power, popularity, fame, connection will conjure interest and admiration from readers (Nwabueze, 2011, p. 6). This was related to the process of selective exposure where only familiar variables intercept both news-photo and readership in a particular area or sections of Nigeria to such news pictures. See Figure 2, Adams Oshiomhole in an unusual style with socially displaced children and Figure 3, Amina Namadi Sambo, Vice President's wife hosting the Super Falconets of Nigeria. Such pictures are aristocratic and testimonial in nature. These Figures enunciated the nature of those visual news features that were meant to interconnect the readers with their idols and personages. And Figure 3, also carried an indication for wrongly placed jump-head and the possibilities of misdirecting the readers, (see circled jump-head).

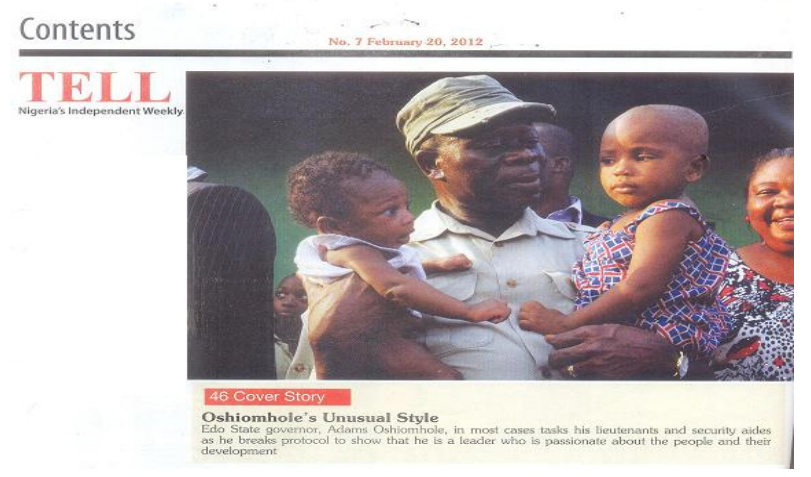

Figure 2. Governor Adams Oshiomhole of Edo State, breaking protocol to interact with socially displaced children in his constituency

Source: Tell magazine, page 6, February $20^{\text {th }}, 2012$.

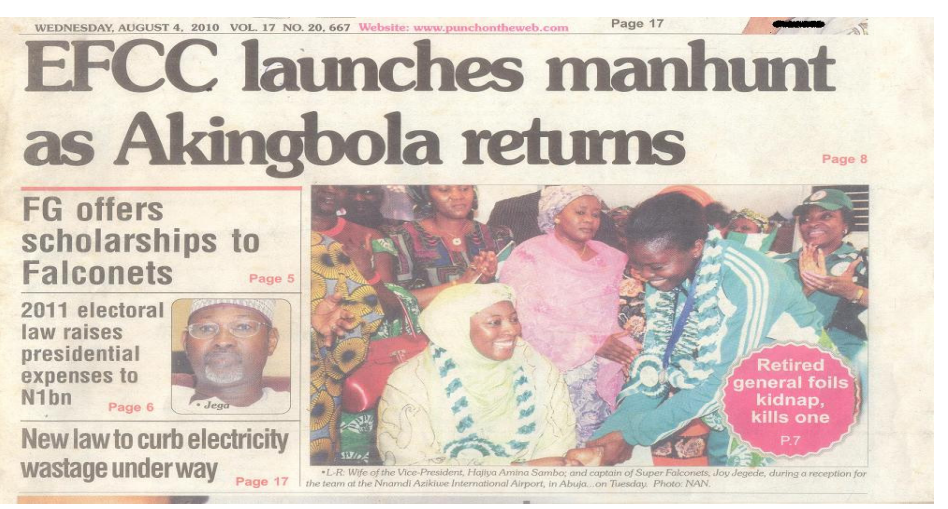

Figure 3. Wife of Nigeria's Vice President, (Amina Namadi Sambo) in a reception party in honour of Super Falconets of Nigeria with wrongly placed jump-head (circled), captioned: Retired general foils kidnap, kills one.

Source: The Punch newspaper, cover page, $4^{\text {th }}$ August, 2010.

\subsection{Impact}

This has to do with the number of persons a photo story affects or likely to affect. Channels $T V$ 95, reported that Ebola Virus Disease (EVD) killed seven thousand persons, created an alarming fear in death toll. Such news-photo had received more attention than the photo story of a car crash that killed three persons (Nwabueze, 2011, p. 8). In this context, the process of selective perception implied that impact was created in the magnitude of readers affected by the news, since they belonged to the same ecology and maintained consistency in pre-existed attitudes and beliefs. Readers' attitudes were beclouded with lingered anxiety of fear when compared to the case of Figure 4. The caption: "Abuja Controversial Killings" had a badly cropped 1" x 1" portrait that did not tally with quantum of killings. This approach reduced the expected visual argument between news pictures and headlines in the printed reportorial. 


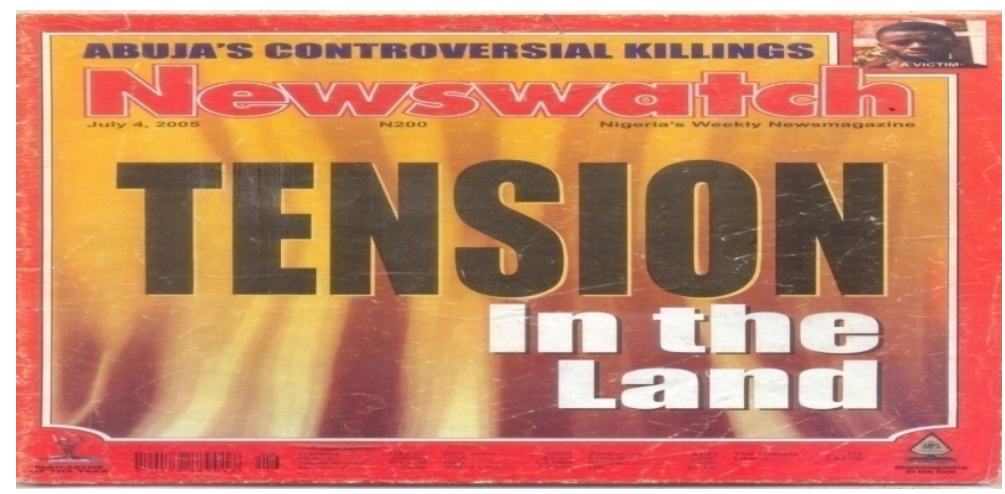

Figure 4. A badly cropped portrait (frustrated a catchy headline)

Source: Newswatch, cover page, July $4^{\text {th }} 2005$.

\subsection{Proximity}

Nwabueze deals with this as the closeness or nearness of an event to the readership. This closeness could be physical or psychological. Physical nearness comes when for instance Nigerian newspapers give priority placement to events that occurred within the country (Nwabueze, 2011: 9), to stories of militant groups, Boko Haram attacks such as "Tension in the Land" see Figure 4. Comparatively in Nigeria, there are fewer news stories on natural disasters, such as earthquakes or hurricanes than in the United States of America and Asian countries. Process of selective perception implored the news print readers into reading what they interpreted as being in consonance with psychological affections to their preexisting attitudes and beliefs.

\subsection{Conflict}

Picture stories about controversies, quarrels, disagreements, friction, challenges, struggles against odds, etc., will capture interest of reporters as newsworthy events, issues or topics. The sensationalized stories about disagreements in picture stories are made to involve drama of stirring emotions in attracting more attention than picture stories on agreements without conflicting elements (Nwabueze, 2011, p. 9). See Figure 5, on "2007, Year of Electoral Frauds, Landmark Judgments, and Decaying Infrastructure," created variances in process of selective retention which will establish divergent views between the news pictures and larger section of the print media readers.

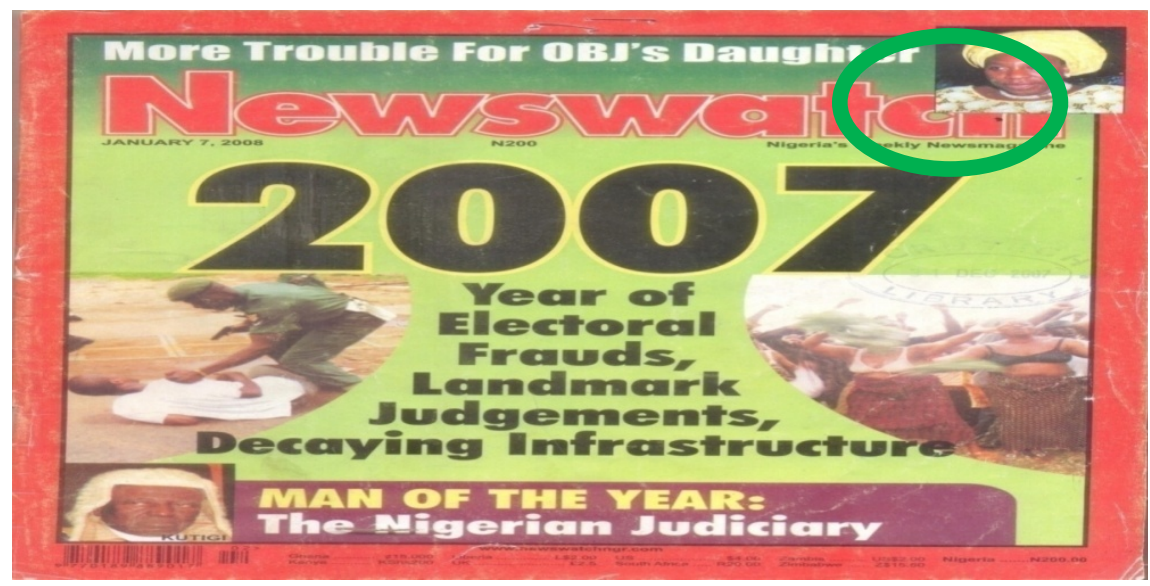

Figure 5. Portrait of Obasanjo's daughter blocking 'ch' of the nameplate (visual noise)

Source: Newswatch, cover page, $7^{\text {th }}$ January, 2008

\subsection{Human Interest}

Unlike prominence which basically considers the elite status of the news personality, human interest deals with how a story affects any class of human beings. It considers human angle of a story, that is, the human feeling aspect of a report and its likelihood to elicit affection from the readership, (Nwabueze, 2011, p. 10). This is applicable to "Oshiomhole's Unusual Style," breaking protocol to appreciate his Edo State peasants and their development strides. In Figure 2, this picture created a compassionate relationship with the headline and in the process of selective exposure, where empathy was established in favour of human interest. 


\subsection{Oddity}

Events that are unusual or that are different from routine experiences also get classified as newsworthy picture stories. A picture story on citizens arresting a policeman would receive more attention than routine arrests of civilians by policemen. People get excited when reading about unusual events (Nwabueze, 2011, p. 11).

The pictures are used to give more credibility to the story, especially in this seeing-is-believing era. If for instance, the investigation is linked to the scene of destruction or other gory images, pictures of such scenes are also part of the entire investigation and should be captured by a reporter. The knowledge of photography equips them with the ability to manipulate the camera to achieve such purposes. It helps the reporter march the written observations with visuals. Every complete investigative reporter should own a camera because pictures are very important in investigative reporting, (Nwabueze, 2012, p. 147). To further contract this reasoning, Brown et al. (2010), sees news picture as one of the truest media of acting as voice for the voiceless, speech for the speechless and is also tantamount to a reservoir of information to be re-dug for referencing.

\section{Data Analyzes and Interpretation}

Data collected for the study were analyzed using Chi-square statistical tool. The hypothesis states that there is no significant relationship between print media contents and the public's appreciation of news. The analysis of this hypothesis is presented in Table 1.

Table 1: Chi-square analysis of the relationship between print media contents and the public's appreciation of news

\begin{tabular}{|c|c|c|c|c|c|c|c|c|c|}
\hline $\mathrm{S} / \mathrm{N}$ & ITEMS & $\mathrm{SD}$ & $\mathrm{D}$ & $\mathrm{A}$ & SA & MEAN & SD & $\mathrm{X}^{2}$ & Sig. \\
\hline 1 & $\begin{array}{l}\text { Pictures are important during print media } \\
\text { reporting of news }\end{array}$ & $\begin{array}{l}15 \\
(7.5 \%)\end{array}$ & $\begin{array}{l}14 \\
(7.0 \%)\end{array}$ & $\begin{array}{l}53 \\
(26.6 \%)\end{array}$ & $\begin{array}{l}117 \\
(58.8 \%)\end{array}$ & 3.37 & 0.91 & 141.1 & .05 \\
\hline 2 & $\begin{array}{l}\text { People read news stories that have pictures in } \\
\text { them than those without pictures. }\end{array}$ & $\begin{array}{l}9 \\
(4.5 \%)\end{array}$ & $\begin{array}{l}23 \\
(11.6 \%)\end{array}$ & $\begin{array}{l}99 \\
(49.7 \%)\end{array}$ & 68 & 3.14 & 0.79 & 103.2 & .05 \\
\hline 3 & $\begin{array}{l}\text { The efficacy of news reporting can be judged by } \\
\text { the pictorial content. }\end{array}$ & $\begin{array}{l}23 \\
(11.6 \%)\end{array}$ & $\begin{array}{l}27 \\
(13.6 \%)\end{array}$ & $\begin{array}{l}59 \\
(29.6 \%)\end{array}$ & $\begin{array}{l}90 \\
(45.2 \%)\end{array}$ & 3.09 & 1.02 & 59.1 & .05 \\
\hline 4 & $\begin{array}{l}\text { Print media news with pictures gain more } \\
\text { attention than those without pictures. }\end{array}$ & $\begin{array}{l}64 \\
(32.2 \%)\end{array}$ & $\begin{array}{l}26 \\
(13.1 \%)\end{array}$ & $\begin{array}{l}58 \\
(29.1 \%)\end{array}$ & $\begin{array}{l}51 \\
(25.6 \%)\end{array}$ & 2.48 & 1.19 & 16.8 & .05 \\
\hline 5 & $\begin{array}{l}\text { News makes more meaning to people when } \\
\text { presented with large pictures. }\end{array}$ & $\begin{array}{l}9 \\
(4.5 \%)\end{array}$ & $\begin{array}{l}30 \\
(15.1 \%)\end{array}$ & $\begin{array}{l}65 \\
(32.7 \%) \\
\end{array}$ & $\begin{array}{l}95 \\
(47.7 \%)\end{array}$ & 3.24 & 0.87 & 87.1 & .05 \\
\hline
\end{tabular}

Results in Table 1 above revealed that a greater percentage of the respondents agreed with the statement that pictures are very important during print media reporting of news, therefore, pictures affected public perception of news $($ Mean $=$ 3.37; SD .91; $\mathrm{x}^{2}=141.08 ; \mathrm{p}<.05$.) Also, most of the respondents established that people read news that had pictures in them than those without pictures (Mean $=3.14 ; \mathrm{SD}=.79 ; \mathrm{x}^{2}=103.21 ; \mathrm{p}<.05$.) In addition, majority of the respondents also agreed with the statement that the efficacy of news reporting can be judged by the pictorial content (Mean $=3.09$; $\left.\mathrm{SD}=1.02 ; \mathrm{x}^{2}=59.07 ; \mathrm{p}<.05\right)$. Therefore, the null hypothesis, which stated that there was no significant relationship between print media contents and the public's appreciation of news, was rejected. The alternate hypothesis was formulated which stated that there was a significant relationship between print media contents and the public's appreciation of news.

\section{Implication of Major Findings}

From the result, $49.7 \%$ respondents agreed that people preferred to read news that had pictures in them than news without pictures; this is in agreement with Defleur and Everett (2013) who explained that a picture is news. When something happens, it is recorded by photojournalists, who package it in a form that could be understood by a reader and publishes it through a medium. Many events worth reporting take place at the same time in different places. The one that gets selected, gets highlighted, and gets published becomes news. Except an account of an event passes through this process, it is no news. News picture is a report that presents a contemporary view of reality with regard to a specific issue, event or process (Defleur and Everett, 2013, http://www.amazon.com/). 47.7\% of the respondents agreed that news make more meaning to people when supported with large pictures. The result of this analysis was in correspondence with that of Lester (2011) who stated that essentially, print media communications are bound by large, banner headlines with big, dramatic pictures and short, easy-to-read stories. These are tactics used by newspaper graphic designers to attract news readers (pp. $181-182$ ).

$58.8 \%$ of the respondents strongly agreed that pictures are important during print media reporting of news. This finding agreed with Akpan (2000) who explained that an editorial picture in most cases remain argumentative. As communication form, it is very rhetorical in nature in that it has to use every available means of persuasion. There are, therefore, two very important segments of an editorial picture: (a) a brief display of a current event this has to be an event of significance and (b) interpretation, an appraisal of that event, for the sole purpose of getting the reader or viewer to think like the photojournalist for the editorial picture. The event must have been reported somewhere in the 
media, and the editorial press photographer is trying to throw more light on the issue. For one to be able to picture good editorials, press photographer needs to be familiar with rhetoric. Rhetoric, as the art of using every available means of persuasion, compels the editorial photojournalist to approach editorial photography from the angle of group dynamics, shun frivolity tendencies but encourages 'win win' and 'generality' tendencies (p. 68).

\section{Conclusion}

Hitherto, the literature has not documented any study on the need to involve the print media in accepting the news pictures as investigative and interpretative vehicles for effective visual journalism in the interest of a print reading public. In that light, this effort is fresh, unique and quite commendable in the eye of print production and readership perception of news picture in a collaborative survival with written words.

The study, therefore, concluded that these issues of effective presence of news pictures had surfaced because of sharing qualitative level of selective perception that had existed between the news consumers and media publications, such relationship should not be anamorphous. This act further reduces mediocrity and expedites professionalism by valvegating uncensored contributions. Empathy was replicated in the news picture, which interned attraction and credibility in the reported news. Obviously, poor wages, in-conducive working conditions for photojournalists have plagued Nigeria's print industries for quite some time and have amortized professional hands in favour of ad-hoc staffing. Other lingering reasons included the nonchalant attitude of photojournalists towards training and developing themselves on the job which could hinder their creative techniques that would have constructively aided them in retaining selective retention in news perception.

\section{Recommendations}

From abinitio, the Chameleonic trait prepossesses picture as news which has always been inviting and deposited on the basis of standardized orientation in blending creativity with technology. The following recommendations will empower this motion and juxtapose the practice of photojournalism in a good working relationship with other journalists, by fostering a new identity for print media reportage in Nigeria; these are:

i). In maintaining standards, photojournalists intending to work with the magazine and newspaper corporations should possess a minimum qualification of an Ordinary National Diploma (OND) in Mass Communication, Journalism or a Certificate in Photojournalism.

ii). All investigative photojournalists should promote creativity by starting with the understanding that press pictures should adhere to the journalistic $2 \mathrm{~W}$ 's and $\mathrm{H}$ ('why' issues that led to the climax in the picture? 'What' is the currency of the action in the picture taken? 'How' is the manner of expressing the most communicable action in the news picture?). And, also, dexterity in counter-balancing suitable selection of words with press pictures must be handled with care.

iii). Practicing journalists and photojournalists should uphold the tenets of the profession and respect the codes of ethics of journalistic practice so that they can guard against intrusion into people's privacy and libelous offences in the performance of their duties. Frequently stated ethics on protection from invasion of privacy and obscene publications should be clearly published in the print media. The essence for respecting codes of journalistic practice is also intended to guard against unnecessary litigations, brutality and harassment that may be caused by the photojournalist's ignorance.

\section{References}

Akinfeleye, R. (2011). Essentials of journalism: An introductory text. Lagos: Malt House.

Akpan, E. D. (2000). Editorial writing. Des Wilson (ed.) Introduction to Print Media: Readings in Nigerian Journalism. Lagos: Stirling-Horden Publishers.

Baran, S. J. (2002). Introduction to mass communication: media literacy and culture, $2^{\text {nd }}$ ed. USA: McGraw-Hill Higher Education.

Brown, N. J., Bassey-Duke, V. E., Iji, E. M., \& Okon, O. (2010). Echoes of photojournalism in Nigeria's Tell and Newswatch magazines. Annals of Humanities and Development Studies, 1(2).

Channels TV 95. (2014). A DStv cable news channel.

Defleur, M. L., \& Everett, D. (2013). Understanding mass communication. http://www.amazon.com/understandingmass-communication-Melvin-Defleur/dp/0395674042

Effiom, V. (2005). Reporter's handbook: A practical approach to news reporting. Calabar: Balyhen. 
Goshgarian, G., Krueger, K., \& Minc, J. B. (2003). Dialogues: An argument, rhetoric and reader. Boston: Pearson Custom Publishers.

Hess, H. (1975). Pictures as arguments. London: Sussex University Press.

Highered. (2014). http://highered.mcgraw-hill.com/sites/dl/free/002483962/42557/tub83962_ch04.pdf

Lester, P. M. (2011). Visual communication: Images with messages, $5^{\text {th }}$ ed. Australia: Wadsworth Cengage Learning.

Media. (2014). http://mediacarmeliteracy.tumbir.com/

National Open University of Nigeria, (NOUN) (2014). http://nou.edu.ng/NOUN_OCL/pdf/SASS/MAC\%20211.pdf

Ngwu, C. C., \& Ugwu, J. C. (2013). Releasing the watchdog: A critical analysis of the internal and external forces against the investigative and watchdog functions of the press in Nigeria's democratic setting. African Media and Democracy Journal, 1(1), 280.

Nwabueze, C. (2011). Reporting: Principles, approaches, special beats. Owerri: Top-shelve.

Nwabueze, C. (2012). The art of investigative reporting: A practical guide. Owerri: Top-shelve.

Photo-chart. (2014). http://www.Photochart.com/pub_9_Photojournalism.html.

Weiser, J. (2009). See what I mean? Photography as nonverbal communication. http://www.phototherapycentre.com/articles/1988_PhTxc.pdf

Wogu, J. (2005). Photojournalism as an instrument of communication. I. Nwosu, J. Aliede \& I. Nsude (eds.) Mass Communication: One Course, Many Professions. Enugu: Prime Targets.

\section{(cc) $\mathrm{BY}$}

This work is licensed under a Creative Commons Attribution 3.0 License. 